\title{
Isolation of Moraxella sp. from Cases of Keratoconjunctivitis in an Organized Sheep Farm of India
}

\author{
Kumaragurubaran Karthik*, Kaliyaperumal Manimaran, Ramalingam Mahaprabhu, \\ Kulasekaran Shoba
}

Central University Laboratory, Madahavarm Milk Colony, Tamil Nadu Veterinary and Animal Sciences University, Chennai, India Email: *karthik_2bvsc@yahoo.co.in

How to cite this paper: Karthik, K., Manimaran, K., Mahaprabhu, R. and Shoba, K. (2017) Isolation of Moraxella sp. from Cases of Keratoconjunctivitis in an Organized Sheep Farm of India. Open Journal of Veterinary Medicine, 7, 138-143. https://doi.org/10.4236/ojvm.2017.710014

Received: August 17, 2017

Accepted: October 23, 2017

Published: October 26, 2017

Copyright $\odot 2017$ by authors and Scientific Research Publishing Inc. This work is licensed under the Creative Commons Attribution International License (CC BY 4.0).

http://creativecommons.org/licenses/by/4.0/

\begin{abstract}
Keratoconjunctivitis in sheep causes severe ocular irritation thereby reducing the production performance thus causing economic loss to the farmers. Bacterial cause of keratoconjunctivitis in sheep may be due to Listeria monocytogenes, Moraxella ovis, Mycoplasma conjunctivae, etc. An investigation carried out at Tirupathur, Sivagangai district, Tamil Nadu, India revealed keratoconjunctivitis in sheep (population 100 animals). Isolation and identification of eye swabs from ailing animals $(\mathrm{n}=5)$ showed that the bacteria was Moraxella sp. Polymerase chain reaction (PCR) of the isolate was positive for Moraxella sp. Antimicrobial sensitivity testing of the isolate showed that it was sensitive to all antibiotics used in the study. This study reports the presence of Moraxella sp. infection in sheep warranting further studies to know the exact status of this organism so as to prevent keratoconjunctivitis in sheep.
\end{abstract}

\section{Keywords}

Moraxella, Keratoconjunctivitis, Sheep, PCR, India

\section{Introduction}

Ocular infections in farm animals can cause serious economic loss to farmers [1] [2] [3]. Keratoconjunctivitis is a painful condition that can lead to temporary or permanent eye blindness in sheep. Clinical signs like serous lacrymation, increased blinking, hyperaemia, ulcers and blepharospasm which can be noticed initially in one eye and later both eyes may be affected. In the later stages the serous lacrymation may become purulent [4] [5]. Affected animals usually recover within weeks but some remain infected for longer period and this can lead 
to reduced feed intake thus affecting the slaughter weight [6]. Several bacterial species namely Listeria monocytogenes, Moraxella ovis, Mycoplasma conjunctivae, Chlamydophila pecorum, Coxiella burnetii, etc., were isolated from sheep affected with keratoconjunctivitis [3] [5] [7]. Moraxella bovis was attributed as the cause of infectious keratoconjunctivitis (IBK) in cattle and later findings reported that another agent namely $M$. bovoculi was also the cause of IBK in cattle [8]. M. bovis was also reported from sheep but the frequency of its isolation is less [9]. Reports regarding the isolation of Moraxella sp. from animals in India are scarce [10] [11] [12] and very recently a report of $M$. bovoculi in cattle was recorded by Karthik et al. [13]. The present communication describes the isolation, biochemical and molecular characterization of Moraxella sp. from sheep in an organized sheep farm in India.

\section{Materials and Methods}

\subsection{Sample Collection and Bacteriological Investigation}

Investigation carried out at an organized sheep farm at Tirupathur, Sivagangai district, Tamil Nadu, India during February 2017, showed that 5 out of 100 sheep had eye infection. Affected animals were about 3 years old and the farm had mixed age group animals. On clinical examination affected sheep's had lacrymation and ulceration in one or both eyes. Eye swabs were collected aseptically without any preservatives from the affected sheep and they were transported and processed within 4 hours at the Central University Laboratory, TANUVAS, Chennai-51. Swabs were cultured on 5\% sheep blood agar, MacConkey agar and nutrient agar and incubated at $37^{\circ} \mathrm{C}$ overnight. Biochemical tests like catalase, oxidase, indole (I), methyl red (MR), voges proskauer (VP) and citrate $(\mathrm{C})$ tests were carried out as described earlier [14]. Pure isolates were subjected to antibiotic sensitivity testing (ABST) on Mueller-Hinton agar using amyoxyclav, enrofloxacin, ciprofloxacin, cefixime, gentamicin, tetracycline and norfloxacin as per the standard protocol [15].

\subsection{Polymerase Chain Reaction and Sequencing}

DNA from isolated culture were extracted by heating a loop full of colonies in $100 \mu \mathrm{L}$ nuclease free water at $95^{\circ} \mathrm{C}$ for $10 \mathrm{~min}$ followed by cooling at $-20^{\circ} \mathrm{C}$ for $10 \mathrm{~min}$ and centrifuged at $10,000 \mathrm{rpm}, 18^{\circ} \mathrm{C}$ for $10 \mathrm{~min}$. Supernatant was used as the DNA for polymerase chain reaction (PCR). PCR was carried out as per Angelos \& Ball [16] using published primers targeting the 16S-23S intergenic spacer region and products were run on $2 \%$ agarose gel and results were documented using Bio Rad Gel Doc XR ${ }^{+}$system. DNA of Moraxella bovoculi isolate from the laboratories repository was used as the positive control and non template PCR mixture was kept as the negative control during the PCR reaction. Further positive PCR product was purified using QIA quick gel extraction kit (Qiagen, USA) following manufacturer's protocol and was send for sequencing to Eurofins Genomics India, Bangalore, India. Obtained sequences were aligned and NCBI 
BLAST search was used to find the matching sequences available in the data bank.

\section{Results and Discussion}

Two samples after overnight incubation on blood agar revealed small drycolonies showing hemolysis under the colony (Figure 1). Correspondingly growth was also noticed on nutrient agar while MacConkey does not yield any growth. Other three samples do not yield any growth on all the three media used for isolation. Microscopic examination of the colonies revealed gram negative bacilli organisms. Biochemical tests like catalase and oxidase yielded positive results while other tests yielded negative result. Antibiotic sensitivity test revealed that the isolate was sensitive to all the antibiotics used in the drug sensitivity test. PCR reaction yielded an amplicon size of $\sim 650$ bp which may correspond to $M$. bovis, $M$. boevrei, and M. caprae (Figure 2). Sequences result was matching $99 \%$ with the M. bovis.

Keratoconjunctivitis is a serious problem of the eye noticed in several animal species and it can cause economic loss to the farmer. Causative agent of this condition is many and among infectious agents in sheep bacterial origin namely Listeria monocytogenes, Moraxella ovis, and Mycoplasma conjunctivae are predominant [5]. Several cases of keratoconjunctivitis in sheep goes unnoticed hence incidence of this condition is not clear. This investigation report the isolation of Moraxella sp. from two affected sheep and the isolate has $99 \%$ similarity with $M$. bovis. Though $M$. bovis is the predominant organism of IBK in cattle its frequency of isolation from sheep is less. M. ovis has been documented by several

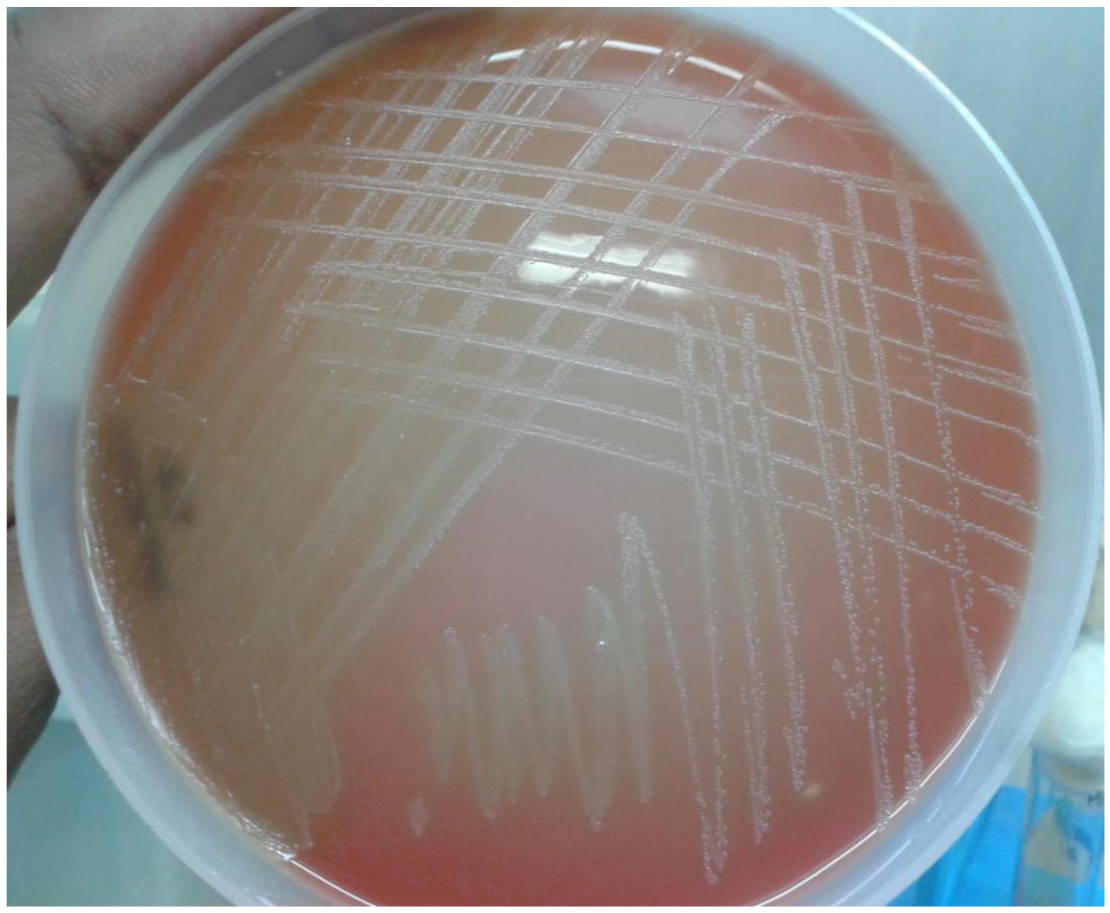

Figure 1. Blood agar showing haemolytic colonies. 


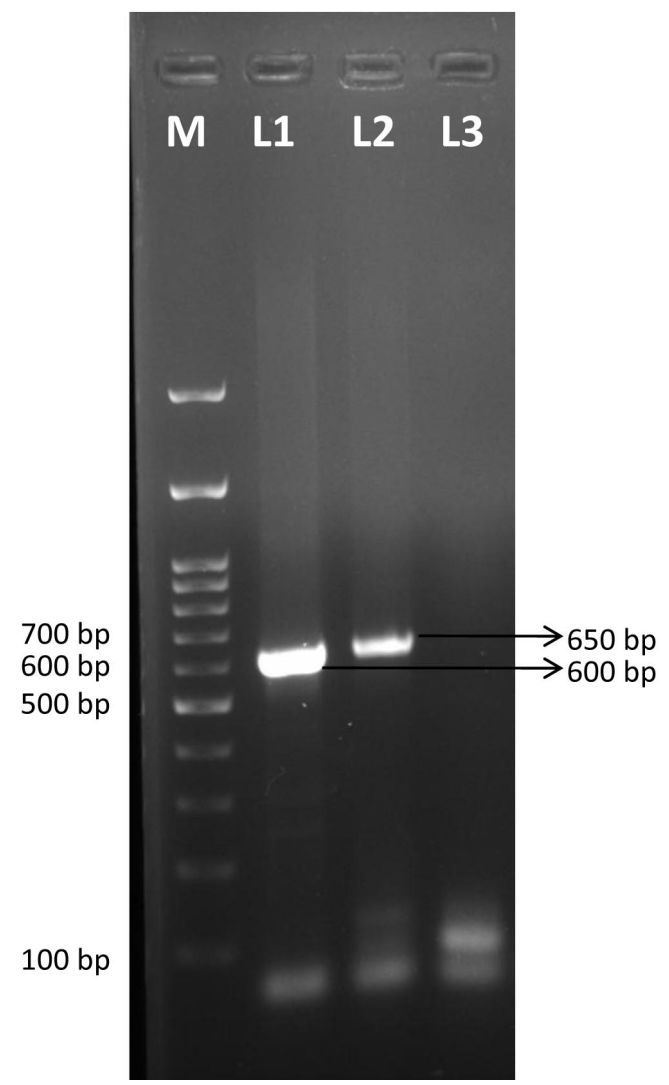

Figure 2. Agarose gel image of 16S-23S intergenic spacer region PCR for detection of Moraxella sp. M-100 bp ladder (New England Biolabs; Cat No. N3236S). L1-Moraxella bovoculi (GenBank sequence id. KX121047) showing specific band at $\sim 600$ bp. L2-Sheep eye swab sample showing band at $\sim 650 \mathrm{bp}$ (specific for Moraxella sp.).

authors from sheep [7] [9] [17]. Several authors though report the isolation of Moraxella sp. from sheep there is no clear picture regarding its role in keratoconjunctivitis in sheep [18] [19] [20]. There are reports of isolation of $\mathcal{S}$. aureus, Corynebacterium spp. and E. coli from cases of keratoconjunctivitis in sheep [5]. Antibiotic sensitivity testing results showed that the isolate was sensitive to all the antibiotics used which was in concordance with earlier reports [9]. There are only few reports on Moraxella sp. from India [10] [11] [12] [13]. Hence further studies has to be carried out in this part of the world to know the exact status of Moraxella infection and also to carve out a better prevention measure to minimize the economic loss to the farmers. Vectors namely house fly and face fly plays major role in transmission of the pathogen hence vector control should also be carried out to effectively control the infection [6].

\section{Conclusion}

Current investigation reports the presence of Moraxella sp. in sheep causing keratoconjunctivitis. Hygienic farm practices can minimize vector control thereby can prevent vector transmission of Moraxella sp. Further studies need to be carried out to know the virulence factors of Moraxella sp. causing keratoconjuncti- 
vitis in sheep.

\section{Acknowledgements}

The authors are thankful to Tamil Nadu Veterinary and Animal Sciences University for supporting this work.

\section{Conflict of Interest}

The authors declare that they have no competing interest.

\section{Disclosure Statement}

The authors declare that they have no competing interest.

\section{References}

[1] Whittaker, C.J.G., Gelatt, K.N. and Wilkie, D.A. (1999) Food Animal Ophthalmology. In: Gelatt, K.N., Ed., Veterinary Ophthalmology, 3rd Edition, Lippincott Williams \& Wilkins, Philadelphia, PA, 1117-1176.

[2] Waldridge, B.M. and Colitz, C.M.H. (2002) Diseases of the Eye. In: Pugh, D.G., Ed., Sheep and Goat Medicine, 1st ed., W.B. Saunders Company, Philadelphia, PA, 317-339. https://doi.org/10.1016/B0-72-169052-1/50014-4

[3] Smith, M.C. and Sherman, D.M. (2009) Ocular System. I: Goat Medicine, 2nd Edition, Wiley-Blackwel, Hoboken, New Jersey, 257-273. https://doi.org/10.1002/9780813818825.ch6

[4] Egwu, G.O., Faull, W.B., Bradbury, J.M. and Clarkson, M.J. (1989) Ovine Infectious Keratoconjunctivitis: A Microbiological Study of Clinically Unaffected and Affected Sheep's Eyes with Special Reference to Mycoplasma conjunctivae. Veterinary Record, 125, 253-256. https://doi.org/10.1136/vr.125.10.253

[5] Åkerstedt, J. and Hofshagen, M. (2004) Bacteriological Investigation of Infectious Keratoconjunctivitis in Norwegian Sheep. Acta Veterinaria Scandinavica, 45, 19-26. https://doi.org/10.1186/1751-0147-45-19

[6] Angelos, J.A. (2010b) Moraxella. In: Gyles, C.L., Prescott, J.F., Songer, J.G. and Thoen, C.O., Eds., Pathogenesis of Bacterial Infections in Animals, Fourth Edition, 469-481. https://doi.org/10.1002/9780470958209.ch24

[7] Dagnall, G. (1994) The Role of Branhamella ovis, mycoplasma conjunctivae and Chlamydia psittaci in Conjunctivitis of Sheep. British Veterinary Journal, 150, 65-71. https://doi.org/10.1016/S0007-1935(05)80097-1

[8] Angelos, J.A. (2010a) Moraxella bovoculi and Infectious Bovine Keratoconjunctivitis: Cause or Coincidence? Veterinary Clinics of North America: Food Animal Practice, 26, 73-78. https://doi.org/10.1016/j.cvfa.2009.10.002

[9] Maboni, G., Gressler, L.T., Espindola, J.P., Schwab, M., Tasca, C., Potter, L. and de Vargas, A.C. (2015) Differences in the Antimicrobial Susceptibility Profiles of $\mathrm{Mo}$ raxella bovis, M. bovoculi and M. ovis. Brazilian Journal of Microbiology, 46, 545-549. https://doi.org/10.1590/S1517-838246220140058

[10] Gandhi, A., Sharma, M., Dhar, P., Katoch, V., Thakur, A. and Kumar, R. (2008) Isolation of Moraxella bovis from Frozen Bovine Semen and Determination of $\mathrm{Mi}$ crobial Load. Indian Journal of Microbiology, 48, 405-407.

https://doi.org/10.1007/s12088-008-0049-7 
[11] Jeyabal, L., Debdatta Ray, D., Sureshkannan, S., Nagarajan, K., Visnuvinayagam, S., Ghosh, S., Banerjee, P.S., Sekar, S.C., Bagath, M., Padmanath, K., Rajarajan, K. and Ravikumar, P. (2013) First Report of Morexella bovis Infection in Indian Cattle. Advances in Animal and Veterinary Science, 1, 202-204.

[12] Vaid, R.K., Anand, T., Bera, B.C., Shukla, B.N., Nagar, D.K., Singh, G., Virmani, N., Barua, S., Singh, B.K. and Singh, R.K. (2014) Isolation and Molecular Identification of Moraxella ovis and Moraxella spp. from Infectious Keratoconjunctivitis in Sheep in India. Journal of Veterinary Science and Technology, 5, 3.

[13] Karthik, K., Mahaprabhu, R., Roy, P. and Raman, M. (2017) Emergence of Moraxella bovoculi Associated with Keratoconjunctivitis in an Organized Dairy Farm of India. Proceedings of the National Academy of Sciences, India, Section B: Biological Sciences. https://doi.org/10.1007/s40011-017-0884-6

[14] Quinn, P.J., Markey, B.K., Carter, M.E., Donnelly, W.J. and Leonard, F.C. (2002) Veterinary Microbiology and Microbial Disease. Iowa State University Press, Ames, 536.

[15] Bauer, A.W., Kirby, W.M., Sherris, J.C. and Turck, M. (1966) Antibiotic Susceptibility Testing by a Standardized Single Disk Method. American Journal of Clinical Pathology, 45, 493-496.

[16] Angelos, J.A. and Ball, L.M. (2007) Differentiation of Moraxella bovoculi sp. nov. from Other Coccoid Moraxellae by the Use of Polymerase Chain Reaction and Restriction Endonuclease Analysis of Amplified DNA. Journal of Veterinary Diagnostic Investigation, 19, 532-534. https://doi.org/10.1177/104063870701900511

[17] Abdullah, F.F.J., Naidu, N.R.G., Sadiq, M.A., Abba, Y., Tijjani, A., Mohammed, K., Chung, E.L.T., Norsidin, M.J.M., Lila, M.L.M., Haron, A.W., Aziz, A., Saharee and Omar, A.R. (2015) Prevalence of Moraxella ovis Infection in Goats under the Ladang Angkat Programme, Universiti Putra Malaysia: A Cross-Sectional Study. IOSR Journal of Agriculture and Veterinary Science, 8, 99-102.

[18] Lindqvist, K. (1960) A Neisseria Species Associated with Infectious Keratocnjunctivitis of Sheep Neisseria ovis nov. spec. Journal of Infectious Diseases, 106, 162-165. https://doi.org/10.1093/infdis/106.2.162

[19] Dagnall, G.J. (1994) An Investigation of Colonization of the Conjunctival Sac of Sheep by Bacteria and Mycoplasmas. Epidemiology and Infection, 112, 561-567. https://doi.org/10.1017/S0950268800051268

[20] Hansson, N.E., Lindqvist, Å. and Wierup, M. (1984) Moraxella ovis Isolerat vid ett utbrott av keratokonjunktivit i en fårbesättning. [Moraxella ovis Isolated at an Outbreak of Keratoconjunctivitis in a Sheep's Herd.] Sven. vet. Tidn., 36, 823-826. 